\title{
Umbilical mucosal polyp in an infant: a rare entity Mimicking umbilical granuloma
}

\author{
Archana Shetty ${ }^{1}$, Shubha H.V ${ }^{2}$, Vijaya $C^{3}$, Venkatachalapathy $V^{4}$ \\ ${ }^{1}$ Dr. Archana Shetty, Associate Professor, Department of Pathology. ${ }^{2}$ Dr. Shubha H.V, Assistant Professor, Department \\ of Pathology, ${ }^{3}$ Dr. Vijaya C., Professor \& amp; Head Department of Pathology. ${ }^{4}$ Dr. Venkatachalapathy V, Department \\ of Pediatric Surgery, all authors are affiliated with Sapthagiri Institute of Medical Sciences \& amp; Research Centre, \\ Bangalore, Karnataka, India.
}

Corresponding Author: Dr. Shubha HV, Assistant Professor, Department of Pathology, Sapthagiri Institute of Medical Sciences and Research Centre, Hesaraghatta Main Road, Bangalore, Email: drshubhahv@gmail.com

\begin{abstract}
Umbilical lesions constitute a comparatively lesser percentage of the specimens received on a daily basis for histopathological examination. During embryological development, the umbilicus functions as a channel that allows flow of blood between the placenta and fetus. It also serves an important role in the development of the intestine and the urinary system. After birth, once the umbilical cord falls off, no evidence of these connections should be present. Nevertheless a few lesions are encountered related to the same. Patients with umbilical disorders present with drainage, a mass, or both. Umbilical granuloma, omphalomesenteric remnants, urachal remnants, hernias are few lesions in the umbilical region. We present a case of an umbilical polyp in an infant, which clinically suspected to an umbilical granuloma. The idea behind presenting this case was that, not only are umbilical polyps rare lesions but also it is necessary to differentiate it from umbilical granuloma as the treatments may vary. The clinicians and reporting pathologists must be aware of this rare congenital lesion.
\end{abstract}

Key words: Congenital, omphalo mesenteric duct, umbilical granuloma, polyp, silver nitrate

\section{Introduction}

Congenital umbilical disorders represent a group of diverse anomalies according to the embryonic remnant found in the umbilicus [1]. Umbilical granulomas, polyps, patent vitello intestinal duct, cysts area few such lesions. Umbilical polyp is one such lesion, which

\section{Case Report}

A one year two months old male infant was referred to the Department of paediatric surgery of our hospital with the complaint of a non-healing remnant lesion in the region of the umbilicus.

The mother complained of occasion al bloody spots on the lesion. She also gave the history of application of topical ointments for the lesion after consulting a local doctor, how ever there was no change in the same.

No complaints of excessive crying/discomfort associated with the swelling were given. The baby was born at full term with no associated complications. Developmental milestone still date were normal. On examination, a small cherry-red nodular swelling was seen protruding out from the umbilicus [Figure 1].

Surface of the swelling was smooth and glistening. Adjacent skin appeared unremarkable. Ultrasonography of the abdomen was normal.

Manuscript received: $4^{\text {th }}$ May 2018

Reviewed: $14^{\text {th }}$ May 2018

Author Corrected: 20 $0^{\text {th }}$ May 2018

Accepted for Publication: $23^{\text {rd }}$ May 2018

Pathology Update: Tropical Journal of Pathology \& Microbiology Available online at: www.pathologyreview.in 163 | P a g e 


\section{Case Report}

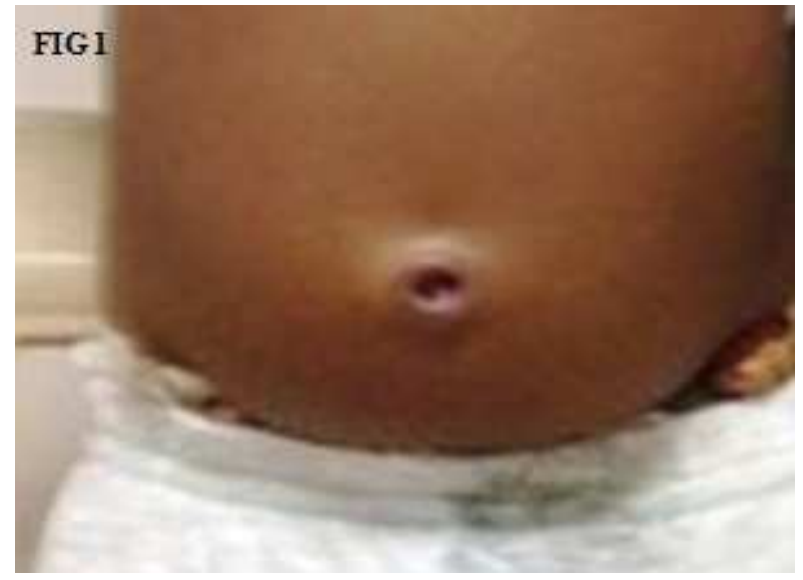

Fig-1: Abdomen of the infant showing an elevated polypoid lesion in the umbilical region

With a clinical diagnosis of the umbilical granuloma, the nodule was excised and sent for the histopathological examination. Gross examination revealed a polypoidal lesion covered one it her side by tiny strips of skin. Nodule measured $1 \times 0.8 \mathrm{cms}$ across. Cut section of nodule was soft and grey white.

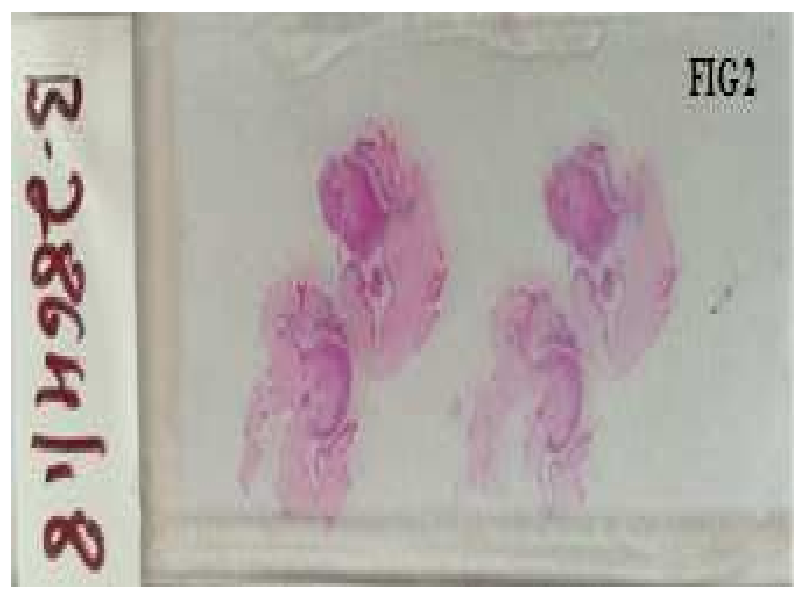

Figure-2: Tissue section showing the umbilical polyp in continuity with the skin lining on either side, $\mathrm{H}$ and $\mathrm{E}$ stain.

Microscopy of the polypoidal lesion showed small intestinal mucosa showing normal villi and crypts. Also seen in the sub mucosa were lymphoid follicles of varying sizes. Both the inner and outer muscular layers of the ileum were seen.

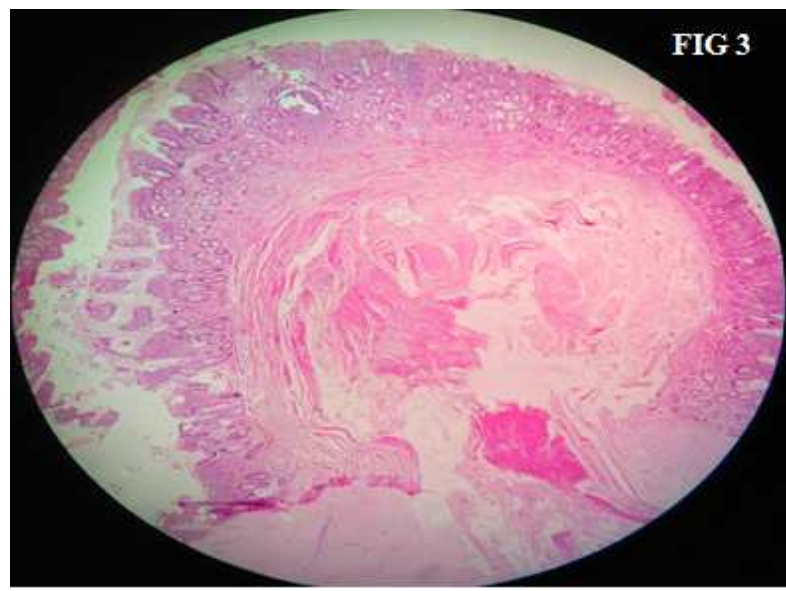

Figure-3: Umbilical polyp showing the small intestinal mucosal lining, $\mathrm{H}$ and $\mathrm{E}$ stain, $\mathrm{X} 40$. 
Case Report

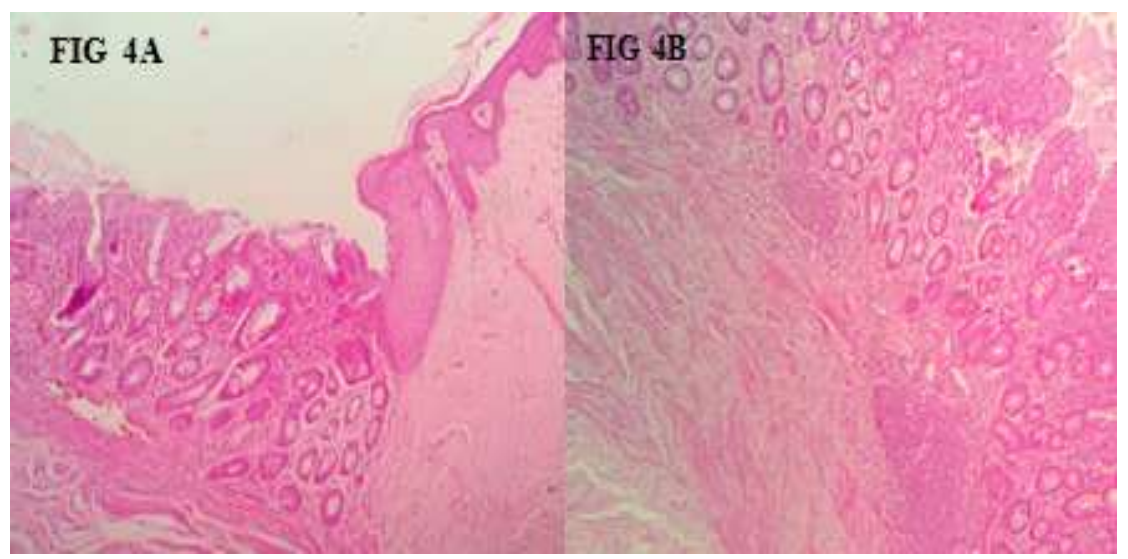

Figure 4A: The junction of small intestinal mucosa and the epidermis of skin, $H$ and $E$ stain, $X 100$.

Figure 4B: Histology of the polyp showing all the four layers of the ileum including Peyer's patches, $\mathrm{H}$ and $\mathrm{E}$ stain, X100.

Adjacent skin covered tissue fragments were unremarkable. A diagnosis of umbilical polyp was conferred upon. The infant had an uneventful postoperative stay and was discharged after five days. A follow up visit six weeks later showed no recurrence of the lesion.

\section{Discussion}

During the initial development al stages of intrauterine life, abroad communication develops between hemidgut and yolk sac. With fetal growth and elongation of the intestinal tract, this communication narrows, giving way to the omphalo mesenteric duct. This structure is obliterated and loses its intestinal attachment by the end of the fifth to sixth intrauterine week; together with the yolk sac remnants, it is absorbed into the umbilical cord [3]. The umbilical cord then dries out and separates 2 to 3 weeks after the delivery and the underlying skin recovers, leaving no sign soft he cord. Total or partial impairment in closure of the omphalo mesenteric duct, which can happen in $2 \%$ of the new born, can result in a number of conditions, including umbilical enteric fistula, umbilical sinus, omphalomesenteric duct cyst, Meckel's diverticulum and umbilical polyp [4].

An umbilical polyp is one such congenital anomaly which represents the external remnant of the omphalo mesenteric duct. Umbilical polyps are generally regarded as innocuous but may be associated with other vitello-intestinal duct defects [4]. With an umbilical polyp, the umbilical region remains bright red with a granular appearance following the separation of the stump.

Clinically an umbilical polyp presents as a red, firm, round tumor with mucoid and / or blood tinged secretions in neonates. It bleeds easily, resists local treatment, is painless, and continues for months to years. Usually it is associated with visceral connections and is composed of gastric mucosa, intestinal mucosa, and pancreatic tissues and in exceptional cases ectopic gastro intestinal mucosa also has been reported. A study of such polyps done by Helwigetalon 40 cases showed gastric mucosa to be the predominant type of tissue comprising the polyp [5].

Umbilical polyp scan be mistaken clinically for other common umbilical disorders such as umbilical granulomas and pyogenic granulomas. Umbilical granulomas are dry and velvety lesions. All the mentioned lesions may present with symptoms of umbilical discharge or hyperemia in the surroundings kin $[6,7]$.

The presence of an umbilical polyp may indicate a persistent omphalomesenteric duct, which may result complications such as an intra-gastro-intestinal connection leading to prolapse or herniation of gastro intestinal contents, or as in our case, a communication with the bladder resulting in persistent urinary discharge. Ultrasound and / or Computed Tomography is ideally recommended to rule out the associated intraabdominal anomalies, if any [4].

Histopathological examination [HPE] of all the umbilical lesions is recommended due to similar clinical presentations as mentioned above. Even in our case the lesion was sent for HPE suspecting it to be a case of umbilical granuloma. The polyp in our case was composed of ileal tissue as expected in an umbilical 
polyp as discussed above. The base of the polyp was in continuity with the stratified squamous epithelium of the epidermis. Histology of umbilical granulomas show edematous tissue with proliferating fibroblasts and capillaries. The lesion often shows collections of inflammatory cells $[2,8]$.

Cauterization of an umbilical polyp with silver nitrate solution or salt application is neither effective nor does it respond to conservative treatment unlike umbilical granuloma which responds to the same after two or three applications of silver nitrate [9].

The preferred treatment for umbilical polyp is surgical excision under aseptic condition, as it is not only curative, but also confirms the histology of the underlying tissue comprising the polyp. Early diagnosis of this lesion can facilitate the treatment and decrease the risk from associated complications.

\section{Conclusion}

An umbilical mucosal polyp is a distinct congenital lesion attributed to the remnant omphalo mesenteric duct. This lesion does not respond to conservative modes of treatment unlike umbilical granuloma with which it shares similar clinical features. Complete excision is not only diagnostic but also curative. The clinicians and reporting pathologists must be aware of this rare entity.

Funding: Nil, Conflict of interest: None initiated Permission from IRB: Yes

\section{References}

1. Miyagi H, Honda S, Minato M, Okada T, Hatanaka KC, Taketomi A. Impact of umbilical polyp resection: A report and literature review. Afr J Paediatr Surg. 2016 Oct-Dec;13(4):196-198.doi:10.4103/0189-6725. 194677.

\section{Case Report}

2. Gaopande VL, Deshmukh SD, Khandeparkar SS, Suryavanshi MA, Patil VR. Clinical and histopathological profile of lesions of umbilicus. Medical Journal Of DY Patil University. 2015;8(2):179-81. doi: 10.4103 / 0975-2870.153152

3. Pacilli M, Sebire NJ, Maritsi D, Kiely EM, Drake DP, Curry JI, et al. Umbilical polyp in infants and children. Eur J Pediatr Surg. 2007 Dec;17(6):397-9.

4. Pomeranz A. Anomalies, Abnormalities and Care of the umbilicus. Pediatr Clin North Am. 2004 Jun;51 (3): 819-27, xii.

5. Steck WD, Helwig EB. Cutaneous remnants of the omphalomesenteric duct. Arch Dermatol. 1964 Nov;90: 463-70.

6. Karagüzel G, Aldemir H. Umbilical Granuloma: Modern understanding of etiopathogenesis, diagnosis, and management. J Pediatr Neonatal Care. 2016; 4(3): 00136. doi: 10.15406/jpnc.2016.04.00136

7. You Y, Yang X, Hao F, Zhong B. The umbilical polyp: A report of two cases and literature review.Int $\mathrm{J}$ Dermatol. 2009 Jun; 48 (6):630-2. doi: 10.1111/j.13654632. 2009.03880.x.

8. Brady M,Conway AB,Zaenglein AL,Helm KF. Umbilical Granuloma in a 2 month old patient: Histopathology of a common clinical entity. Am J Dermatopathol. 2016 Feb; 38 (2):133-4. doi:10.1097/ DAD. 0000000000000429

9. Piparsaliya S, Joshi M, Rajput N, Zade P. Patent Vitellointestinal Duct: A close differential diagnosis of umbilical granuloma: A case report and review of literature. Surgical Science. 2011;2(3):134-6 doi:10. 4236/ss.2011.23027.

\section{How to cite this article?}

Archana Shetty, Shubha H.V, Vijaya C, Venkatachalapathy V. Umbilical mucosal polyp in an infant: a rare entity Mimicking umbilical granuloma. Trop J Path Micro 2018;4(2):163-166. doi: 10.17511/jopm.2018.i2.08 